\title{
TARI GUEL SEBAGAI IDENTITAS MASYARAKAT GAYO
}

\author{
Gustira Monita \\ Jurusan Tari Fakultas Seni Pertunjukan Institut Seni Indonesia Yogyakarta \\ Email:gustiramonitaa@gmail.com
}

\begin{abstract}
ABSTRAK
Tari Guel dipahami sebagai sebuah simbolis gerak yang memberikan interaksi dinamis pada penontonnya, yaitu tentang pembentukan makna dalam realitas kehidupan sehari-hari oleh-orangorang Gayo. Dalam memahami bentuk keseluruhan ataupun makna yang terkandug di dalamnya Tari Guel lebih mengutamakan rasa. Tari Guel juga dipandang sebagai museum gerak tak benda yang menyimpan banyak sejarah masyarakat Gayo. Guel adalah identitas penting suku Gayo, menyimpan banyak simbol sejarah yang sudah sepatutnya dipecahkan dan diungkapkan. Agar suku Gayo dan keberadaannya tidak hilang terbawa arus modernisasi. Penelitian ini menggunakan pendekatan Antropologi, yang memandang seni sebagai bagian dari aktivitas budaya manusia. Pendekatan Antropologi digunakan untuk melihat konteks, yang akan membedah kehidupan sosial masyarakat dan adat istiadat Gayo, yang berkaitan dengan Tari Guel dan keberadaannya yang masih dijaga serta dilestarikan oleh masyarakat Gayo. Selain itu penelitian ini juga menggunakan pendekatan Koreografis. Pendekatan ini adalah sebagai teks yang digunakan untuk membedah bagaimana bentuk penyajian dan keseluruhan struktur yang terdapat pada Tari Guel.
\end{abstract}

Kata Kunci: Tari Guel, Suku Gayo, Aceh.

\begin{abstract}
Guel dance is understood as a symbolic movement that provides dynamic interaction to the audience, namely about the formation of meaning in the reality of daily life by the Gayo people. In understanding the overall form or meaning contained in it, Guel Dance prioritizes taste. The Guel dance is also seen as a museum of intangible objects that holds much of the history of the Gayo people. Guel is an important identity of the Gayo tribe, holding many historical symbols that should be solved and revealed. So that the Gayo tribe and its existence will not be lost in the current of
\end{abstract}


modernization. This research uses the Anthropology approach, which views art as part of human cultural activities. Anthropology is defined as the science of humans, specifically about their origin, race, customs, beliefs in the past, society and culture. Anthropology used as a context, which will dissect the social life of the people and the customs of Gayo, relating to the Guel Dance and its existence which is still preserved and preserved by the Gayo people. Besides this research also uses a choreographic approach. This approach is a text used to dissect the form of presentation and overall structure contained in the Guel Dance.

Keywords: Guel Dance, Gayo Tribe, Aceh.

\section{PENDAHULUAN}

Indonesia dikenal sebagai sebuah negara yang memiliki berbagai variasi kesenian tradisional yang beragam dan sangat menarik. Tarian tradisional merupakan suatu tarian yang berkembang pada setiap daerah. Umumnya, karya tari ini diadaptasi dari kebiasaan secara turun temurun dan telah menjadi budaya pada masyarakat tertentu. Keberagaman akan kesenian tradisional membuat setiap daerah yang ada di Indonesia memiliki ciri khas tersendiri dalam perwujudan identitas kebudayaannya. Keberadaan tarian tradisional yang ada di setiap daerah selalu mengalami perkembangan, sehingga tanpa disadari tarian tradisional yang diwariskan dari generasi ke generasi selalu mengalami pasang surut.

Melihat dari fenomena peradaban baru yang perlahan memasuki setiap wilayah di Indonesia, perlu adanya upaya pelestarian kesenian tradisional terutama oleh putra dan putri daerah setempat agar tidak hilang oleh perkembangan zaman. Tari Guel merupakan sebuah tarian tradisional masyarakat Gayo yang merupakan salah satu suku di Provinsi Aceh. Gayo adalah sebuah wilayah yang berada di salah satu bagian punggung Pegunungan Bukit Barisan yang membentang sepanjang pulau Sumatera. Suku Gayo menetap di bagian tengah Provinsi Aceh, sebuah dataran tinggi yang dikelilingi oleh pegunungan dan perbukitan.

Secara administratif suku Gayo tersebar dalam beberapa kabupaten kota yaitu kabupaten Bener Meriah, Aceh Tengah, Gayo Lues, dan beberapa desa di kabupaten Aceh Tenggara. Masyarakat suku Gayo sendiri enggan disebut sebagai suku Aceh. Hal ini dikarenakan suku Gayo memiliki unsur kebudayaan yang sangat berbeda dengan 
masyarakat Aceh pesisir pada umumnya. Gayo memiliki sebuah kerajaan yang bernama kerajaan Linge, berpusat di Kabupaten Aceh Tengah kota Takengon kecamatan Isaq, desa Buntul Linge. Kerajaan ini telah runtuh sekitar $900 \mathrm{M}$.

Kerajaan Linge memiliki sistem pemerintahan tersendiri yang disebut sarak opat. Sistem ini mengatur segala aspek kehidupan masyarakat Gayo.

Sarak opat terdiri atas Raja, alim ulama, pemangku adat, dan rakyat. Di dalamnya meliputi adat istiadat, norma, nilai, hukum, dan hal-hal yang dilarang dalam menjalani kehidupan sehari-hari. Termasuk juga unsur kebudayaan yang terus berkembang dan masih dipraktikkan hingga saat ini.

Orang Gayo mempunyai adat istiadat yang khas, berbagai ungkapan tersirat dalam berbagai macam pepatah dengan beraneka makna yang sangat sulit untuk diterjemahkan ke dalam bentuk tulisan maupun lisan. Salah satunya adalah ungkapan Asal Linge Awal Serule.

Ungkapan tersebut diyakini oleh masyarakat Gayo bahwasanya Urang Gayo berasal dari Linge dan berawal dari Serule. Tidak ada yang mengetahui pasti apa maksud dari pepatah ini. Hanya saja masyarakat Gayo meyakini mereka berasal dari Linge, sebuah kerajaan yang berdiri kokoh di Gayo.
Adapun Serule adalah sebuah nama pemukiman pertama yang berada di Linge dan merupakan pusat peradaban suku Gayo itu sendiri. Melalui Serule inilah kebiasaan masyarakat Gayo berkembang pesat dan secara tidak langsung budaya yang terjadi di Serule menjadi identitas suku Gayo. Kerajaan Linge pada masa kejayaannya, adalah pusat pemerintahan suku Gayo. Bahkan salah satu putra kerajaan Linge telah memberikan konstribusi besar terhadap berkembangnya kerajaan Aceh yang dulu kedaulatannya sampai ke Negeri Johor Malaysia. Kerajaan Linge tidak asing bagi seluruh penduduk di tanah Aceh. Suatu kerajaan yang tidak diketahui kapan dan siapa yang mendirikannya, bahkan seakan-akan seperti suatu kerajaan yang berdiri (terbentuk) dengan sendirinya namun diyakini sebagai cikal bakal sebuah pemerintahan yang berasal dari Linge (Asharyadi, 2008:27).

\section{PEMBAHASAN}

Guel adalah kata dalam bahasa Gayo yang memiliki beberapa arti. Secara denotatif, kata Guel berarti bunyi atau membunyikan. Kata ini dipergunakan untuk melakukan kegiatan yang terarah pada hal-hal yang akan menghasilkan bunyi. Hal ini terlihat pada saat akan dimulainya pertunjukan Guel. Biasanya para ceh akan meminta kepada pemusik 
dengan berkata guelen atau bunyikan, sebagai tanda akan dimulainya pertunjukan Guel.

Secara konotatif kata Guel mengandung arti sebagai sebuah awalan dan juga keseluruhan tari tersebut. Ada keterkaitan antara judul tari dengan keseluruhan tarian ini. Guel yang berarti awalan adalah introduksi, kata ini diucapkan sebelum gerakan dan tarian diawali, dimulai, atau dilakukan. Dalam pertunjukan, Guel adalah keseluruhan tarian, keseluruhan pertunjukan, dan seluruh rangkaian aktivitas yang terjadi di dalamnya.

Tari Guel merupakan sebuah tarian tradisional yang lahir dari legenda setempat yaitu legenda Gajah Putih. Legenda ini bercerita tentang kisah kepiluan kakak beradik di ruang lingkup kerajaan Linge Gayo. Kedua kakak beradik itu bernama Sengeda dan Bener Meriah, yang merupakan putra kandung dari Raja Linge ke XII. Berawal dari mimpi Sengeda, yang seolah bertemu dengan abangnya Bener Meriah yang tewas terbunuh karena rasa dengki dan dikhianati oleh saudara tirinya.

Dalam mimpinya Bener Meriah menjelma menjadi Gajah Putih dan menunjukkan bagaimana menjinakkan Gajah tersebut. Gajah itu nantinya akan dipersembahkan ke Kesultan Aceh Darussalam. Proses menjinakkan Gajah Putih tersebut lah yang menjadi inspirasi terciptanya Tari Guel. Di dalam mimpi itu Bener Meriah menyebut cara-cara yang harus dilakukan Sengeda untuk menangkap Gajah Putih. Gajah yang merupakan penjelmaan Bener Meriah itu akan bangkit dan bergerak bila diiringi dengan irama tertentu. (Munif, 2006:36)

Secara koreografis Tari Guel merupakan sebuah tarian berpasangan yang dilakukan oleh dua orang penari laki-laki. Masingmasing penari memiliki peran tersendiri, satu orang memerankan tokoh Gajah Putih atau Bener Meriah dan satu orang lagi berperan sebagai penjinak Gajah atau Sengeda. Ada empat babakan wajib atau struktur dalam Tari Guel. Struktur ini terbagi berdasarkan cerita dan sangat erat kaitannya dengan adegan, pola gerak, dan iringan musiknya.

Adapun empat babak dalam struktur Tari Guel adalah munatap, redep, ketibung, dan cincang nangka. Babak ini juga sangat terkait dengan sejarah Tari Guel. Gerakan yang terdapat dalam babak ini secara keseluruhan merupakan simbolis dan representasi dari alam. Transisi gerak yang dipakai bernama dep yang dilakukan berulang kali pada setiap perpindahan babak. Terkecuali pada babak ketibung menuju ke babak cincang nangka yang dilakukan secara terus menerus dengan menambah tempo serta kekuatan dan energi pada gerak. 
Dalam bagian ini juga tampak perbedaan unsur ruang dan waktu yang dilakukan oleh penari. Pola sikap dalam Tari Guel terdiri dari sikap kepala, yakni tangak dan tungkuk. Sikap badan cenderung tegap. Sikap tangan terdiri dari bahu kanan dan kiri, lengan atas, lengan bawah, pergelangan tangan, dan kedua telapak tangan. Gerakan tangan ini sering disebut sebagai likak ni рити. Sedangkan sikap kaki disebut jinyit, sesuk, dan lumpet.

Pola gerak yang menjadi ciri khas Tari Guel itu terletak pada kaki dan bahu dengan motif gerak kaki yang disebut gretek dan gerakan bahu yang diputar ke depan dan belakang. Gerak paling terkenal adalah motif gerak dalam babak munatap, yaitu gerakan yang menggambarkan telinga dan belalai gajah. Guel adalah tipe tari Dramatik, memiliki kisah dan pesan moral yang ditujukan kepada khalayak. Tarian ini masuk dalam kategori improvisation dance history yaitu sebuah seni improvisasi yang memiliki kisah. Tahapan improvisasi ini bisa ditemui di setiap tahapan awal penyajian dengan masing-masing penari yang berbeda.

Setiap penari memiliki ciri khas tersendiri dalam mengawali Tari Guel. Biasanya tahap improvisasi dilakukan di awal pertunjukan, dan gerakan improvisasi merupakan ciri khas untuk mengawali tarian ini. Untuk babak selanjutnya gerakan akan terus sama sesuai dengan ajaran para generasi sebelumnya yang terus diturunkan sampai saat sekarang ini. Secara filososfis Guel mengandung nilai dan karakteristik suku Gayo itu sendiri. Terdapat juga unsur interaksi antara penari satu dan dua, serta interaksi penari dan penonton dengan amanah atau syair yang disebut sebuku.

Sebuku dalam bahasa Gayo berarti meratap. Istilah sebuku biasa dipakai untuk meratapi seseorang yang telah meninggal dunia atau ketika berpisah dengan orang yang ia sayangi. Namun seiring berjalannya waktu, pemakaian syair sebuku biasanya hanya berpusat pada prosesi adat perkawinan. Di mana seorang wanita akan berpisah dengan orang yang ia sayangi seperti keluarga atau kerabat dekatnya.

Di dalam penyajian Tari Guel penari memakai pakaian tradisional yang khas yakni Kerawang Gayo yang terdiri dari baju, celana, dan kain penutup celana serta $O p o h$ ulen-ulen yang sekaligus merupakan properti tari. Tidak ada riasan khusus, biasanya penari akan tampil natural tanpa riasan wajah. Instrumen pengiring dalam tari Guel terdiri dari gegedem, memong, canang, gong, dan suling uluh. Tari Guel biasanya disajikan pada panggung terbuka, namun dapat disesuaikan dengan kebutuhan acara sehingga dapat juga dipentaskan di dalam ruangan tertutup maupun procenium stage. 
Penelitian tentang Tari Guel merupakan objek utama yang dikaji. Beberapa alasan yang mendasari penelitian ini adalah karena Tari Guel lahir sebagai representasi sejarah yang terjadi pasca kejadian. Tari Guel juga sering dikatakan museum gerak tak benda oleh masyarakat Gayo dan juga masyarakat luar yang menyaksikannya. Hal ini dikarenakan Guel menyimpan sejarah dan cerita yang sangat penting dan berarti bagi masyarakat Gayo melalui gerakan simbolis yang ada pada sajian tarian tersebut. Tarian ini adalah pesan moral tentang pentingnya menegakkan keadilan dan mempertahankan hak-hak setiap individu yang berdampak besar bagi lingkungannya.

Minimnya informasi tentang Tari Guel menyebabkan penelitian tentang Tari Guel menjadi penting agar dapat dijadikan sumber bacaan dan membantu masyarakat luas untuk mengetahui informasi tentang Tari Guel sebagai icon masyarakat Gayo di provinsi Aceh. Kajian ini memakai pendekatan Koreografi dan Antropologi. Koreografi adalah analisis tentang struktur tari sedangkan Antropologi yaitu suatu studi ilmu yang mempelajari tentang manusia baik dari segi budaya, perilaku, keanekaragaman, dan lain sebagainya.

Sebagai sebuah pertunjukan, tari Guel pertama kali diperkenalkan pada khalayak pada tahun 1972 di panggung terbuka dalam acara pembukaan Pekan Kebudayaan Aceh kedua. Dengan penari utamanya yang bernama Ceh Sahaq seorang penari Guel paling populer di Gayo, dan juga diiringi oleh musik tradisional yang ditangani oleh seorang Maestro gegedem (alat musik tradisional Gayo; sejenis rebana) yang bernama Abdullah Syeh Kilang. Ia merupakan seniman serba bisa sekaligus tokoh yang berpengaruh dalam proses penyajian Tari Guel itu dalam bentuk koreografi.

Dalam tradisi masyarakat Aceh, seorang seniman biasanya tidak hanya terfokus pada satu bidang kesenian saja, biasanya seorang seniman tradisional akan menguasai beberapa bidang seni sekaligus. Kebanyak dari seniman Gayo menguasai sarik yang telah mereka dapatkan dari ajaran orangtuanya masingmasing sejak usia dini. Sarik adalah sebuah teriakan khas yang merupakan salah satu rangkaian yang terdapat dalam pertunjukan Tari Guel.

Seiring berjalannya waktu, banyak para seniman setempat yang ikut serta mengembangkan Tari Guel. Hal ini dapat dilihat dari berkembangnya bentuk penyajian Tari Guel namun tanpa menghilangkan rukun yang ada di dalamnya. Dengan perkembangan ini, Tari Guel pun semakin banyak variasi dan versinya. Hal ini dapat dilihat pada beberapa aspek koreografinya, durasi waktu per babak, maupun introduksi awal 
pementasan yang diperpanjang maupun dipersingkat.

Biasanya Tari Guel yang bervariasi muncul pada penyajian untuk penyambutan dan hiburan yang berfungsi untuk memeriahkan suatu acara.

Hal ini berbeda dengan Tari Guel yang dipertunjukkan pada ritual adat yang berfungsi sebagai pelengkap acara adat.

Di dalam arsip kegiatan Pekan Kebudayaan Aceh I (pertama), tari Guel disebut Tari Munatap atau Tari Bedah, merupakan gerak di tempat dengan pola yang monoton, dan dengan langkah perlahan. Suatu gambaran yang dilakukan dalam usaha mengajak bangkit Gajah Putih dari pembaringannya. Kelanjutannya Tari Guel menjelma menjadi resam kerje mungerje (perkawinan), sebagai tari yang hanya dilangsungkan dalam upacara perkawinan, dengan izin dan restu serta disaksikan oleh sarak opat (sistem pemerintahan) kedua belah pihak.

Tari Guel akhirnya merupakan induk (sumber) dari tarian-tarian Gayo secara keseluruhan. Tari Guel berfungsi sebagai pelengkap dalam upacara adat ritual, dan penyambutan tamu kehormatan. Beberapa acara adat Gayo yang harus menghadirkan Tari Guel di dalamnya, di antaranya adalah acara Nek ni Reje yaitu sebuah acara ritual ketika suatu daerah telah memiliki seorang pemimpin baru yang akan dilantik atau dinobatkan. Acara Nirin reje yaitu sebuah acara pelepasan jabatan seorang raja atau pemimpin daerah yang telah habis masa jabatannya, serta acara perkawinan anak-anak dan keturuan raja-raja. Tanpa adanya Tari Guel dalam acara tersebut, maka acara tersebut dianggap tidak sah secara adat.

Bentuk pengembangan dan variasi juga dapat ditemukan pada sarik. Sarik yang biasanya dilakukan hanya sekali, dapat dilakukan menjadi dua sampai empat kali dengan durasi waktu yang berbeda. Tari Guel tidak boleh ditarikan oleh wanita karena dalam adat Gayo hal tersebut adalah tabu atau pamali. Hal ini masih berkaitan dengan syariat Islam yang diterapkan di Aceh di mana gerakan pada perempuan cenderung terbatas karena dikhawatirkan dapat membuka aurataurat pada wanita ketika menari.

Penelitian ini menggunakan pendekatan Antropologi, yang memandang seni sebagai bagian dari aktivitas budaya manusia. Antropologi diartikan sebagai ilmu tentang manusia, khususnya tentang asal-usul, ras, adat istiadat, kepercayaan pada masa lampau, masyarakat dan kebudayaannya. Dalam buku Antropologi Tari dalam Perspektif Indonesia tulisan Sumaryono tahun 2011 dijelaskan bahwa jika ingin mengenal budaya lebih dalam maka istilah participant observer yang 
diungkapkan adalah pedoman dan panduan dalam melakukan penelitian langsung pada masyarakat Gayo.

Antropologi digunakan sebagai konteks, yang akan membedah kehidupan sosial masyarakat dan adat istiadat Gayo, yang berkaitan dengan Tari Guel dan keberadaannya yang masih dijaga serta dilestarikan oleh masyarakat Gayo. Sedangkan untuk menganalisis bentuk penyajian, mengacu pada pendapat Jaqueline Smith terjemahan Ben Suharto. Di dalam bukunya yang berjudul Komposisi Tari: Sebuah Petunjuk Praktis Bagi Guru, dinyatakan bahwa bentuk dapat didefinisikan sebagai hasil pernyataan berbagai macam elemen yang didapatkan secara kolektif melalui vitalitas estetis, sehingga hanya dalam pengertian inilah elemen-elemen tersebut dihayati.

Buku ini dijadikan sebagai teks yang digunakan untuk membedah bagaimana bentuk penyajian Tari Guel pada masyarakat Gayo. Pada Tari Guel tahapan-tahapan proses dan keseluruhan elemen-elemen menjadi penting pada tiap bagiannya, sehingga nantinya elemen tersebut akan membentuk satu kesatuan yang tidak lepas dari bagianbagian terbesar. Maka dengan demikian bentuk merupakan suatu rangkaian yang teratur dalam sebuah penyajian sehingga orang lain akan mudah memahami bagaimana penyajian dari sebuah komposisi tari yang diwujudkan untuk menghasilkan bentuk keseluruhan.

Sedangkan penyajian adalah cara untuk memaparkan, menyampaikan, menghidangkan, menyajikan dan menampilkan suatu hal atau suatu bentuk secara keseluruhan. Kesenian Gayo, khususnya Tari Guel adalah salah satu unsur kebudayaan Gayo. Tari Guel adalah identitas masyarakat Gayo yang memiliki ciri khas sendiri. Ketika berbicara Gayo di tengahtengah dinamika sosial kebudayaan Aceh, kesenian Gayo akan selalu hadir dalam corak yang berbeda. Hal inilah yang membuat kesenian Gayo itu tampak beda dan menarik.

Seperti halnya Tari Guel, saat sebagian besar masyarakat Aceh berbincang ringan dalam pembahasan kesenian dan kebudayaan maka yang mengingatkan mereka tentang Gayo adalah Tari Guel. Baik itu dari segi gerakan yang sangat khas, kostum yang sangat meriah, maupun alunan musik yang ritmis. Selain itu masyarakat Aceh sendiri meyakini bahwa ada sesuatu yang berbeda ketika mereka menyaksikan pertunjukan Tari Guel secara langsung. Bahkan banyak orang Aceh mengatakan bahwa Tari Guel adalah tarian mistis yang sangat sakral dan bukanlah sembarang tari. 
Tari Guel adalah tarian yang memiliki kisah panjang dan penuh dengan sejarah Aceh. Oleh sebab itu Tari Guel merupakan jati diri suku Gayo itu sendiri, dilihat dari berbagai sudut pandang atas keseluruhan dari bentuk penyajian Tari Guel sudah dapat dikatakan dan dikenali bahwa Guel itu adalah Gayo, artinya Tari Guel adalah suatu hal yang dapat mewakili Gayo.

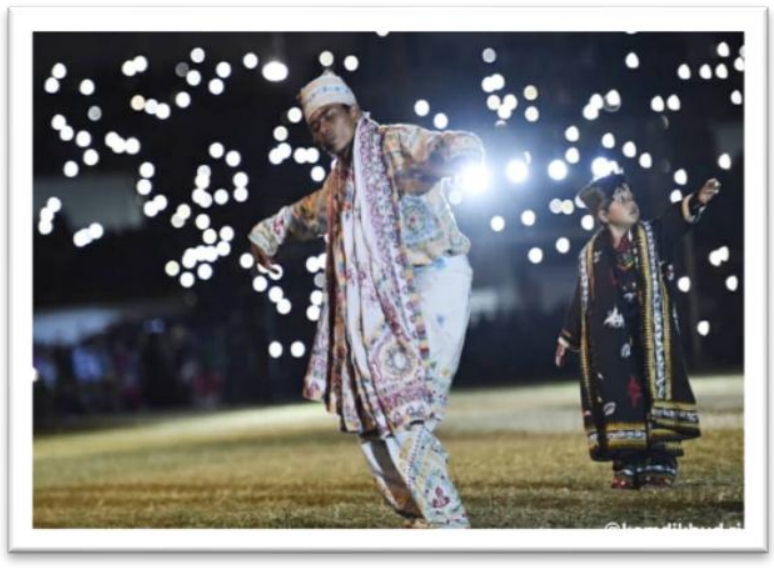

Gambar 1: Teuku Aga, penari Guel dalampembukaan PKA 7 (Dokumentasi: Kemdikbud.RI, 27 Februari 2020)

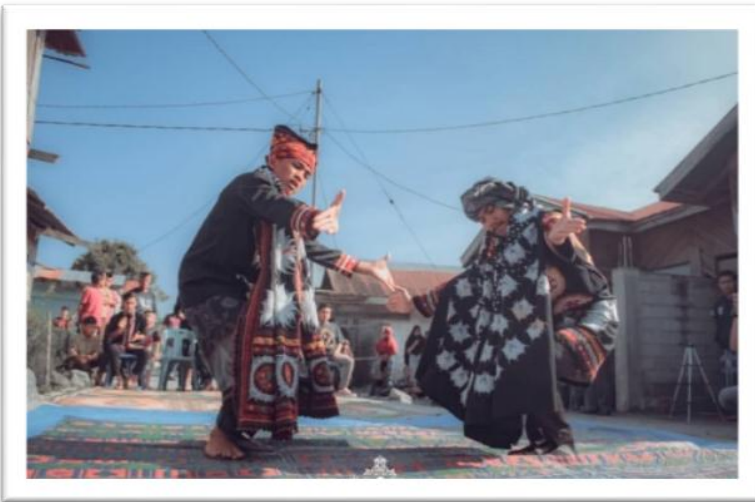

Gambar 2: Dua orang penari Guel dengan pose Cincang Nangka, Dalam acara peyambutan tamu. (Dokumentasi: Sanggar Datok Gayo, 17 Januari 2020)

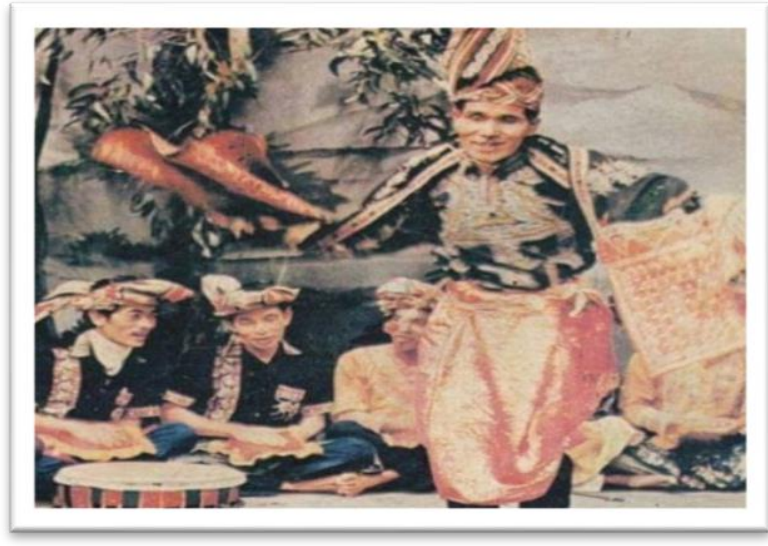

Gambar 3: Penari Guel Gayo yang sering disapa Ceh Sahaq, merupakan seorang penari legendaris yang penah ada di Gayo. (Dokumentasi: Ajli Rahmadi 01 Maret 2020)

\section{PENUTUP}

Analisis bentuk penyajian Tari Guel pada Masyarakat Gayo dapat disimpulkan bahwa bentuk penyajian tari Guel ini mengalami perubahan dan perkembangan secara tehnik penyajian. Hal ini dilandasi dengan kebutuhan acara atau kegiatan yang menghadirkan Tari Guel di dalamnya. Bentuk penyajian tari Guel dalam upacara adat ritual sangat berbeda dengan penyajian untuk kebutuhan hiburan. Hal ini dapat dilihat juga dari perkembangan bentuk penyajiannya yang semakin bervariasi.

Tari Guel dipahami sebagai sebuah simbolis gerak yang memberikan interaksi dinamis pada penontonnya, yaitu tentang pembentukan makna dalam realitas kehidupan sehari-hari. Tari Guel juga 
dipandang sebagai meseum gerak tak benda yang menyimpan banyak sejarah masyarakat Gayo, khusunya pada kejadian di kerajaan Linge pada masa itu. Berbicara tentang keberadaan maupun identitas suku Gayo di Aceh merupakan hal yang sangat menarik dan penting.

Masih sangat banyak hal yang harus diungkapkan terkait sejarah maupun identitas orang Gayo itu sendiri. Melalui Tari Guel ini diharapkan generasi yang akan datang dapat lebih berupaya semaksimal mungkin untuk menjaga identitas budaya dan sukunya. Guel adalah identitas penting suku Gayo sebagai meseum gerak tak benda yang menyimpan banyak simbol sejarah yang sudah sepatutnya dipecahkan dan diungkapkan. Agar suku Gayo dan keberadaannya tidak hilang terbawa arus modernisasi dan menepis sebutan Gayo sebagai Negeri Dongeng itu dengan faktafakta serta penelitian yang dituliskan generasi muda saat ini.

Tari Guel akan terus menjadi identitas masyarakat Gayo yang akan selalu berdampingan dan berkembang dengan kesenian Aceh pada umumnya. Tanpa ada perbedaan suku, budaya, kesenian dan sebagainya. Tari Guel hadir sebagai sarana pemersatu dan pengingat akan cerita kelam yang membentuk sejarah peradaban suku Gayo dan Aceh dalam masa kejayaannya. Kehidupan kebudayaan daerah Gayo dewasa ini sangat menghkawatirkan, karena pewarisan nilai-nilai kebudayaan oleh generasi sekarang dari para pendahulu tidak berjalan sebagaimana yang diharapkan.

Orang-orang tua yang menguasai kebudayaan daerah hanya tinggal beberapa orang saja. Untuk itu tulisan ini merupakan salah satu tindakan dan kesadaran peneliti dalam upaya menjaga khasanah budaya dan kesenian Gayo untuk generasi yang akan datang. Sehingga apabila terjadi hal-hal yang tidak diinginkan terutama tentang masuknya budaya baru yang terus hadir di masyarakat Gayo tulisan ini dapat menjadi referensi dan bermanfaat bagi generasi yang akan meneliti kembali kebudayaan dan sejarah Gayo secara lebih rinci dan lebih luas lagi. Karena sejatinya di daerah Gayo masih banyak hal yang perlu diteliti dan dikemas dalam bentuk tulisan maupun penelitian berlanjut seperti penggalian objek sejarah, kebudayaan, maupun kesenian setempat. 
JOGED: Jurnal Seni Tari p-ISSN 1858-3989 | e-ISSN 2655-3171

\section{DAFTAR SUMBER ACUAN}

Asharyadi. 2008. Lingeku Sayang

Lingeku Malang. Takengon: Percetakan Karisma.

Baihaqi, AK, Dkk. 1981. Bahasa Gayo. Jakarta: Pusat Pembinaan dan Pengembangan Bahasa Departemen Pendidikan dan Kebudayaan

Coubat, A.SY. 1984. Adat Perkawinan Gayo; Kerje Beraturen. Jakarta: Departemen Pendidikan dan Kebudayaan, Proyek Penerbitan Buku Sastra dan Daerah Djamil, M. Junus. 1950. Gajah Putih. Kuta Raja: Lembaga Kebudayaan Atjeh.

Djuned, Daud, M. 1980. Sistem Gotong Royong Dalam Masyarakat Gayo Aceh Tengah. Banda Aceh: Badan Perencanaan Pembangunan Daerah, Provinsi Daerah Istimewa Aceh

HAR Gibb. 1950. Tren Modern Islam, Chichago Illinois, AS: The University of Chicago Press

Hasan, Affan, M, dkk. 1980. Kesenian Gayo dan Perkembangannya. Jakarta: Balai Pustaka

Haviland,William A. Terjemahan R.G Soekadijo. 1999. Antropologi jilid 2 edisi keempat. Jakarta: Erlangga.
Hurgronje, C. Snouck. 1996. Gayo Masyarakat dan Kebudayaannya Awal abad ke 20. Jakarta: Balai Pustaka.

Ibrahim, H. Mahmud, dkk. 2002. Syari`at dan Adat Istiadat. Takengon: Yayasan Maqamam Mahmuda.

Ibrahim, M. Yacob. 1996. Sejarah Adat Istiadat dan Kebudayaan Gayo, Majalah Telangke, Edisi: 5. Medan: Keluarga Gayo Aceh Tengah, KGAT, Medan.

Ismail Suny. 1980. Bunga Rampai Tentang Aceh. Jakarta: Bhratara Karya Aksara

Kadir, Ibrahim, dkk. 1982. Bunga Rampai Cerita Rakyat Gayo. Jakarta: Departemen Pendidikan dan Kebudayaan Proyek Penerbitan Buku Bacaan dan Sastra Indonesia dan Daerah

Koentjaraningrat. 2010. Manusia Dan Kebudayaan di Indonesia. Jakarta: Djambatan.

Koentjaraningrat. 1980. Pengantar Ilmu Antropologi. Jakarta: Aksara Baru

Latief, H.A.R. 1995. Pelanggi Kehidupan Gayo dan Alas . Bandung: Kurnia Bupa. 
Mahmud, Ibrahim dan AR. Hakim Aman Pinan, 2007. Syariat dan Adat Istiadat Jilid 3. Takengon: Yayasan Maqaammahmuda.

14

Majelis Adat Aceh Negeri Gayo. 2007. Kumpulan Butir - Butir Adat Negeri Linge, Qanun Hukum Adat Gayo, Qanun Organisasi Majelis Adat Aceh Negeri Gayo serta Lembaga Wali Nanggroe dan Lembaga Adat. Takengon: Majelis Adat Aceh Negeri Linge

Martono, Hendro. 2012. Ruang pertunjukan dan berkesenian. Yogyakarta: Cipta Media

Melalatoa, M. Junus. 2006. Memahami Aceh Sebuah Perspektif Budaya dalam Aceh, Kembali ke Masa Depan. Jakarta: IKJ Press.

Melalatoa, M.J. 1982. Kebudayaan Gayo. Jakarta: PN. Balai Pustaka

Misdhalina. 2015. Abstarct: Musical Instruments and Flutes. Banda Aceh: Universitas Syah Kuala.
Pinan, A.R, Hakim, Aman. 1998. Hakikat Nilai-Nilai Budaya Gayo Aceh Tengah. Takengon: Pemerintah Kabupaten Aceh Tengah.

Smith, Jacqueline. 1976 . Dance Composition: A Practical Guide For Teacher. London :

Lepus Book, terj. Oleh Ben Suharto. 1985. Komposisi Tari : Sebuah Petunjuk Praktis Bagi Guru. Yogyakarta: Ikalasti Yogyakarta

Smith, Jacqueline. 1985. Komposisi Tari Sebuah Petunjuk Praktis Bagi Guru (terjemahan Ben Suharto, S.S.T). Yogyakarta: Ikalasti

SP, Gustami. Potret Jejak Langkah Seniman Gayo, Catatan Biografi, Pemikiran dan Karya. Jakarta: Pusat studi kebijakan daerah

Spradley, James P. 2006 Metode Etnografi. Yogyakarta: Tiara Wacana.

Sumaryono. 2016. Antropologi Tari dalam Perspektif Indonesia. Yogyakarta: Media Kreativa

Syukri. 2006. Sarak Opat, Sistem Pemerintahan Tanah Gayo dan Relevenasinya Terhadap Pelaksanaan Otonomi Daerah. Jakarta : Hijri Pustaka Utama. 